\title{
Efeito de Períodos de Cultivo e Densidades de Estocagem sobre o Desempenho do Catfish (Ictalurus punctatus) nas Condições Climáticas do Litoral de Santa Catarina
}

\author{
Santo Zacarias Gomes ${ }^{1}$, Antônio Pedro Schlindwein ${ }^{1}$
}

\begin{abstract}
RESUMO - Foram realizados dois experimentos com o objetivo de estudar o efeito do período de cultivo e da densidade de estocagem sobre o crescimento de juvenis de catfish, Ictalurus punctatus. No primeiro experimento, em delineamento estatístico fatorial inteiramente casualizado, estudaram-se os efeitos de duas densidades de estocagem $\left(0,5\right.$ e 0,75 peixes $\left./ \mathrm{m}^{2}\right)$ e de dois períodos de cultivo subseqüentes (com cinco e quatro meses de duração, respectivamente). No segundo experimento, compararam-se duas densidades de estocagem $\left(0,5\right.$ e 0,75 peixes $\left./ \mathrm{m}^{2}\right)$ em um período de cultivo equivalente ao somatório dos dois períodos de cultivo do primeiro experimento. No primeiro experimento, houve efeito estatístico significativo para períodos quanto ao ganho de peso individual, peso médio, biomassa final e ganho de biomassa. Foi observado efeito de densidade de estocagem quanto à biomassa final e ganho de biomassa, não havendo efeito interativo entre as duas variáveis estudadas. O peso individual final e ganho de peso no período de cinco meses de cultivo, com densidades de 0,50 e 0,75 peixes $/ \mathrm{m}^{2}$, foram de 608,1 e 531,4 g e 550,2 e 473,5 g, respectivamente, e no período subseqüente de quatro meses, de 274,2 e 188,3 e 211,3 e 182,3 g, respectivamente. Para biomassa final e ganho de biomassa, os valores observados no período inicial foram, respectivamente, de 298,0 e 262,1 e 397,9 e $354,5 \mathrm{~g} / \mathrm{m}^{2}$, e no período subseqüente, de 132,9 e 89,9 e 179,9 e $119,9 \mathrm{~g} / \mathrm{m}^{2}$, respectivamente. No segundo experimento, não houve efeito estatístico significativo para os parâmetros estudados; os valores de peso individual final, ganho de peso, biomassa final e ganho de biomassa foram, respectivamente, para as densidades de 0,50 e 0,75 peixes $/ \mathrm{m}^{2}, 941,1$ e 758,1;885,1 e 701,2; 491,7 e 587,1; e 463,1 e 535,4 g/m². A sobrevivência média foi de $98 \%$ e os parâmetros físico-químicos da água mantiveram-se dentro da normalidade. Concluiu-se ser viável a produção do Ictalurus punctatus nas condições climáticas em que foi conduzido o estudo.
\end{abstract}

Palavra-chave: catfish, densidade de estocagem, nutrição de peixes, piscicultura

\section{Effect of Two Subsequent Growing Seasons and Stocking Rates on the performance of Channel Catfish (Ictalurus punctatus) in the Climatic Conditions of Coastal Santa Catarina}

\begin{abstract}
Two experiments were performed to study the effect of stocking rate and growing season on the performance of channel catfish (Ictalurus punctatus). In the first experiment, a completely randomized design in a factorial arrangement was used to study the effect of two stoking rates $\left(0.50\right.$ and 0.75 fishes $\left./ \mathrm{m}^{2}\right)$ and two subsequently growing seasons (with five and four month of duration time, respectively). In the second experiment, two stoking rates were compared $\left(0.50\right.$ and $\left.0.75 \mathrm{fishes} / \mathrm{m}^{2}\right)$ in a growing season equivalent to a sum of the two growing season of the first experiment. In the first experiment, there was a significant effect for growing seasons in relation to the individual weight gain, average weight, final biomass and biomass gain. The effect of stoking rate was only observed for final biomass and biomass gain, with non-interactive effect between the two studied factors. The final individual weight and weight gain in the growing season of five months with the stoking rate of 0.50 and 0.75 fishes $/ \mathrm{m} 2$ were 608.1 and $531.4 \mathrm{~g} ; 550.2$ and $473.5 \mathrm{~g}$, respectively. In the subsequently growing season of four months were 274.2 and $88.3 \mathrm{~g}, 211.3$ and $183.2 \mathrm{~g}$, for the two stoking rates, respectively. At the initial growing season the final biomass and biomass gain values were, respectively, 298.0 and $262.1 \mathrm{~g} / \mathrm{m}^{2}, 397.9$ and $354.5 \mathrm{~g} / \mathrm{m}^{2}$, for the two stoking rates, respectively. In the subsequently growing season were 132.9 and $89.9 \mathrm{~g} / \mathrm{m}^{2}$ and 179.9 and $119.9 \mathrm{~g} / \mathrm{m}^{2}$, for the two stoking rates, respectively. In the second experiment, there was no effect for the studied characteristics and the values for the individual final weight, weight gain, final biomass and biomass gain were, respectively, for 0.50 and 0.75 fishes $/ \mathrm{m} 2 \mathrm{socking}$ rates, 941.1 and $758.1 \mathrm{~g} ; 885.1$ and $701.2 \mathrm{~g} ; 491.7$ and $578.1 \mathrm{~g} / \mathrm{m}^{2} ; 463.1$ and $535.4 \mathrm{~g} / \mathrm{m}^{2}$. The average survival was $98.0 \%$ and the water physical-chemical characteristics were considered normal. It was concluded that it is viable to produce the Ictalurus punctatus under the climatic conditions where they were performed.
\end{abstract}

Key Words: catfish, fish nutrition, fish production, stoking rate

\section{Introdução}

O Ictalurus punctatus da família Ictaluridae, ordem Siluriforme, geralmente é criado para consu- mo humano em viveiros de terra escavada, onde a água não é renovada (LEE, 1991). Seu cultivo vem sendo adotado em vários países e a previsão é de que, em 2000, mais de 8000 ha de água serão utilizados 
nesta atividade, somente nos Estados Unidos, onde sua produção intensiva teve início há pouco mais de 20 anos. A produção econômica exige temperaturas com períodos de calor relativamente longos. Sua carne é de alto valor nutritivo e, quando convenientemente preparada, tem excelente paladar. É uma espécie que converte muito bem alimentos inertes em peso, além de constituir-se em excelente alternativa para cultivos intensivos. Sua produtividade por área vem crescendo rapidamente, pois em 1960 era de $1120 \mathrm{~kg} / \mathrm{ha} \mathrm{e}$, atualmente, já é superior a $5640 \mathrm{~kg} / \mathrm{ha}$ (LEE, 1991).

No Brasil, a primeira experiência com esta espécie foi feita em 1972, no Nordeste e, em 1980, iniciouse o cultivo na região Sul (PIEDRAS, 1990). ESQUIVEL GARCIA (1992) investigou seu potencial de crescimento nas condições climáticas do litoral de Santa Catarina, utilizando quatro densidades de estocagem $\left(0,5 ; 0,75 ; 1,0 ;\right.$ e 1,25 peixes $\left./ \mathrm{m}^{2}\right)$ no período de inverno - primavera. Verificou-se que os melhores pesos individuais à despesca foram de 727,1 ; 646,0; e 494,8 g para as três menores densidades de estocagem. A densidade mais adequada foi a de 0,75 peixes $/ \mathrm{m}^{2}$, a qual produziu, no período, $471 \mathrm{~g} / \mathrm{m}^{2} \mathrm{de}$ biomassa, sinalizando um potencial de produção de 4,7 t/hectare em nove meses de cultivo, sem aeração e com pouca renovação de água nos viveiros.

GANNAM e LOVELL (1990), utilizando densidade de 0,75 peixes $/ \mathrm{m}^{2}$, a partir de juvenis de $14,4 \mathrm{~g}$, relataram médias de peso individual de $478 \mathrm{~g}$ em 123 dias, com rendimento de carcaça de $61,2 \%$ e conversão alimentar de 1,15 .

LORIO (1994), em cultivo de catfish, que durou 175 dias, com densidade de estocagem de 7410; 12.300; e 17.300 peixes/ha, obteve os seguintes resultados: 0,59 e $4940 \mathrm{~kg} ; 0,68$ e $8324 \mathrm{~kg}$; e 0,54 e $9361 \mathrm{~kg}$, respectivamente, para peso individual e produção de biomassa/ha nas três densidades. O oxigênio dissolvido médio nos viveiros experimentais com aeração foi de 4,1; 3,7; e 3,7 mg/L, respectivamente.

REIS et al. (1989), trabalhando com catfish na densidade de 0,75 peixes $/ \mathrm{m}^{2}$, em 123 dias (peso inicial de 63,8 g, com ração de $35 \%$ de proteína bruta e 2,9 $\mathrm{kcal}$ de energia digestível/g), obtiveram peso médio final de $493 \mathrm{~g}$, conversão alimentar de 1,15 e rendimento de carcaça de $61,3 \%$, no entanto, BROWN e ROBINSON (1989), também em 120 dias de experimento $(21 \mathrm{~g}$ de peso inicial e densidade de 0,75 peixes $/ \mathrm{m}^{2}$ ), obtiveram peso individual final de $363 \mathrm{~g}$, conversão alimentar de 1,78, sobrevivência de 95 a $97 \%$ e rendimento de carcaça de $52,4 \%$. A qualidade da água mostrou que a amônia variou de 0,1 a $0,9 \mathrm{mg} / \mathrm{L}$ e o oxigênio dissolvido, de 1,4 a 7,8 mg/L.

Segundo LEWIS (1985), a melhor temperatura para o crescimento máximo de catfish está em torno de $29^{\circ} \mathrm{C}$. O mesmo autor considera que seriam necessários, pelo menos, 250 dias do ano com temperatura superior a $15,5^{\circ} \mathrm{C}$ para ser viabilizado o cultivo econômico deste peixe. Entretanto, LOVELL (1989) afirma que o catfish pode atingir $500 \mathrm{~g}$ de peso vivo em seis meses de cultivo, partindo de juvenis com $10 \mathrm{~g}$, desde que a temperatura da água esteja sempre acima de $23^{\circ} \mathrm{C}$.

Com base no exposto acima, objetivou-se estudar o efeito de períodos de cultivo e densidades de estocagem sobre o crescimento do Ictalurus punctatus nas condições climáticas do litoral do Estado de Santa Catarina para ulteriores investigações sobre a viabilidade econômica de cultivo da espécie.

\section{Material e Métodos}

Foram realizados dois experimentos no Campo Experimental de Piscicultura, localizado no Colégio Agrícola de Camboriú (Universidade Federal de Santa Catarina), no município de Camboriú, Estado de Santa Catarina, no período de setembro de 1992 a junho de 1993. Utilizaram-se 12 viveiros de $16,0 \mathrm{~m}^{2}$ com paredes de alvenaria e fundo de terra, providos de sistema de drenagem e abastecimento de água individuais.

No experimento 1, foi estudado o crescimento dos peixes em dois períodos de cultivo, denominados Safra $\mathrm{S}_{1}$ e Safra $\mathrm{S}_{2}$. Os juvenis de Ictalurus punctatus provieram de mesma desova, pesando 56,9 a 57,9 g na Safra $S_{1}$ e 80,0 a 85,9 g na Safra $S_{2}$. O experimento 2 constou de observações num período de 9 meses (correspondente aos períodos das Safras $\mathrm{S}_{1}+\mathrm{S}_{2}$ ), utilizando-se juvenis com pesos variando de 56,9 a $57,9 \mathrm{~g}$.

Os animais foram distribuídos em um delineamento inteiramente casualizado, compondo os seguintes tratamentos em triplicata:

Experimento 1

Tratamento 1 (T1) - Safra $\mathrm{S}_{1}$ com densidade de estocagem de 0,5 peixe $/ \mathrm{m}^{2}$ (8 indivíduos/unidade experimental). Estocagem em 02/09/92 e despesca em 09/02/93.

Tratamento 2 (T2) - Safra $\mathrm{S}_{1}$ com densidade de estocagem de 0,75 peixe $/ \mathrm{m}^{2}(12$ indivíduos/unidade experimental). Estocagem em 02/09/92 e despesca em 09/02/93. 
1268 Rev. bras. zootec.

Tratamento 3 (T3) - Safra $\mathrm{S}_{2}$ com densidade de estocagem de 0,5 peixes $/ \mathrm{m}^{2}$ (oito indivíduos/unidade experimental). Estocagem em 09/ 02/93 e despesca em 02/06/93.

Tratamento 4 (T4) - Safra $\mathrm{S}_{2}$ com densidade de estocagem de 0,75 peixes $/ \mathrm{m}^{2}$ (12 indivíduos/unidade experimental). Estocagem em 10/ 02/93 e despesca em 02/06/93.

Experimento 2

Tratamento 5 (T5) - Safra única, com 0,5 peixe $/ \mathrm{m}^{2}$ (8 indivíduos/unidade experimental). Estocagem em 02/09/92 e despesca em 02/06/93.

Tratamento 6 (T6) - Safra única, com 0,75 peixe $/ \mathrm{m}^{2}$ (12 indivíduos/unidade experimental). Estocagem em 02/09/92 e despescaem 02/06/93.

Para a Safra $\mathrm{S}_{2}$ foram reservados juvenis oriundos do mesmo lote da safra $S_{1}$, em densidade de estocagem de 10 indivíduos $/ \mathrm{m}^{2}$, e submetidos ao manejo de alimentação de mantença.

No experimento 1, a duração dos ciclos de cultivo ou Safras $\left(S_{1}\right.$ e $\left.S_{2}\right)$, foi de cinco e quatro meses subseqüentes, respectivamente. No experimento 2 , a duração foi de nove meses.

A ração utilizada (Tabela 1) continha $32 \%$ de proteína bruta, $5,7 \%$ de extrato etéreo, $4,3 \%$ de fibra bruta, $8,6 \%$ de cinza total, $1,1 \%$ de cálcio, $0,8 \%$ de fósforo e $2670 \mathrm{kcal} / \mathrm{kg}$ de energia digestível, estando dentro dos padrões de exigências nutricionais da espécie, segundo o NATIONAL RESEARCH COUNCIL - NRC (1988).

As taxas de alimentação foram calculadas semanalmente de acordo com FOLTZ (1982), citado por NEW (1987), variando em função da temperatura da água e do peso da biomassa de cada unidade experimental.

A cada 30 dias, foi feita biometria para cálculo das taxas de alimentação, escolhendo-se aleatoriamente uma unidade experimental/tratamento. Os pesos foram então aferidos com $40 \%$ dos animais da unidade sorteada, que serviam de base para cálculo da biomassa das outras unidades do mesmo tratamento.

A temperatura da água dos viveiros foi medida diariamente nos horários de alimentação (10 e 16 h).

Quinzenalmente, procedia-se à análise da água para determinar os níveis de amônia, nitrito e nitrato. Quando a temperatura média da água dos viveiros ultrapassava $25^{\circ} \mathrm{C}$, procedia-se a sua renovação a fluxo constante de 10 litros/minuto em cada unidade experimental. Os
Tabela 1 - Composição química da dieta experimental (na base de matéria natural)

Table 1 - Chemical composition of experimental diet (as fed basis)

Ingredientes \% na dieta

Ingredients $\%$ in diet

Farinha de peixe 20,0

Fish meal

Farelo de soja $\quad 39,5$

Soybean meal

Milho 27,0

Corn

Farelo de trigo $\quad 10,0$

Weat bran

Óleo de soja $\quad 1,0$

Soybean oil

Óleo de peixe $\quad 1,0$

Fish oil

Fosfato bicálcico $\quad 1,0$

Dicalcium phosphate

Premix mineral vitamínico $\quad 0,5$

Vitamin and mineral premix

Antioxidante (Etoxiquim) $\quad 0,015$

Antioxidant (Etoxiquim)

Composição bromatológica

Chemical composition

\begin{tabular}{|c|c|}
\hline Proteína bruta (\%) & 32,2 \\
\hline Crude protein (\%) & \\
\hline Extrato etéreo $(\%)$ & 5,7 \\
\hline Ether extract (\%) & \\
\hline Fibra bruta (\%) & 4,3 \\
\hline Crude fiber (\%) & \\
\hline $\begin{array}{l}\text { Cinzas totais (\%) } \\
\text { Ashes (\%) }\end{array}$ & 8,6 \\
\hline Cálcio(\%) & 1,1 \\
\hline $\begin{array}{l}\text { Calcium (\%) } \\
\text { Fósforo (\%) }\end{array}$ & 0,8 \\
\hline $\begin{array}{l}\text { Phosphorus (5\%) } \\
\text { Energia digestível }(\mathrm{kcal} / \mathrm{kg}) \\
\text { Digestible energy }(\mathrm{kcal} / \mathrm{kg})\end{array}$ & 2670,0 \\
\hline
\end{tabular}

peixes despescados foram pesados individualmente $\mathrm{e}$ dois animais de cada unidade experimental, separados para análise de rendimento de carcaça.

As características analisadas foram: peso individual à despesca, ganho de peso individual, conversão alimentar, rendimento de carcaça, peso da biomassa à despesca, ganho de biomassa e taxa de sobrevivência.

No experimento 1,0 modelo estatístico atendeu à seguinte formulação:

$$
\mathrm{Y}_{\mathrm{ijk}}=\mathrm{m}+\mathrm{s}_{\mathrm{i}}+\mathrm{t}_{\mathrm{j}}+\mathrm{ts}_{(\mathrm{ij})}+\mathrm{e}_{\mathrm{ijk}},
$$

$\mathrm{Y}_{\mathrm{ijk}}=$ características analisadas;

em que

$\mathrm{m}$ = média;

$\mathrm{s}_{\mathrm{i}} \quad=$ efeito do safra $\mathrm{i}(\mathrm{i}=1, \ldots 2) ;$

$\mathrm{t}_{\mathrm{j}} \quad=$ efeito de densidade de estocagem $\mathrm{j}(\mathrm{j}=1,2)$;

st $_{(\mathrm{ij})}=$ efeito interativo do tratamento $\mathrm{S}$ com densidade de estocagem j; e

$\mathrm{e}_{\mathrm{ijk}}=$ resíduo. 
No experimento 2, utilizou-se modelo inteiramente casualizado com dois tratamentos em triplicata:

em que

$$
\mathrm{y}_{\mathrm{jk}}=\mathrm{m}+\mathrm{tj}+\mathrm{e}
$$

$\mathrm{y}_{\mathrm{jk}}=$ característica observada;

$\mathrm{m}=$ média; $\mathrm{e}$

$\mathrm{e}_{\mathrm{jk}}=$ resíduo.

Em ambos experimentos, as médias foram comparadas pelo teste Tukey e as decisões estatísticas, tomadas a $5 \%$ de probabilidade de erro.

\section{Resultados e Discussão}

$\mathrm{Na}$ Tabela 2 estão apresentados os valores de temperatura da água de cultivo a cada mês e a cada semana, no decorrer dos ciclos de cultivo, variando de 20 a $30,6^{\circ} \mathrm{C}$ na Safra $\mathrm{S}_{1}$ com média de $25,6^{\circ} \mathrm{C}$ e de 16,5 a $30,3^{\circ} \mathrm{C}$ na Safra $\mathrm{S}_{2}$ com média de $25,5^{\circ} \mathrm{C}$.

$\mathrm{O}$ aumento semanal da temperatura da água ocorreu lentamente a partir do mês de setembro $\left(\right.$ Safra $\left.\mathrm{S}_{1}\right)$ e decresceu, também lentamente, a partir do mês de maio $\left(\mathrm{Safra}_{2}\right.$ ) até atingir média de $16,5^{\circ} \mathrm{C}$ na primeira semana de junho. Considerando as temperaturas da água em ambos experimentos, observaram-se valores semelhantes, variando de 24,8 a $25,6^{\circ} \mathrm{C}$.

O oxigênio dissolvido variou de 3,5 a $7,9 \mathrm{mg} / \mathrm{L}$; a amônia, de 0,3 a $0,7 \mathrm{mg} / \mathrm{L}$; o nitrito, de 0,05 a $0,06 \mathrm{mg} / \mathrm{L}$; e a transparência, medida com disco de Sechi, de $20 \mathrm{a} 40 \mathrm{~cm}$.

Os valores de peso individual (inicial e final), ganho de peso, conversão alimentar aparente, taxas de sobrevivência, rendimento de carcaça, biomassa, incial e final e ganho de biomassa do experimento 1, estão apresentados na Tabela 3 , observando-se que os valores de peso individual iniciais variaram de 56,9 a 57,9 g e os pesos finais, de 211,3 a 608,1 g. Os valores de ganho de peso individuais variaram de $182,3 \mathrm{~g}$ na Safra $S_{2}$ - densidade de estocagem de 0,75 peixes $/ \mathrm{m}^{2}$,

Tabela 2 - Temperaturas médias $\left({ }^{\circ} \mathrm{C}\right)$ da água na período experimental Table 2 - Average temperature $\left({ }^{\circ} \mathrm{C}\right)$ of the water in the experimental period

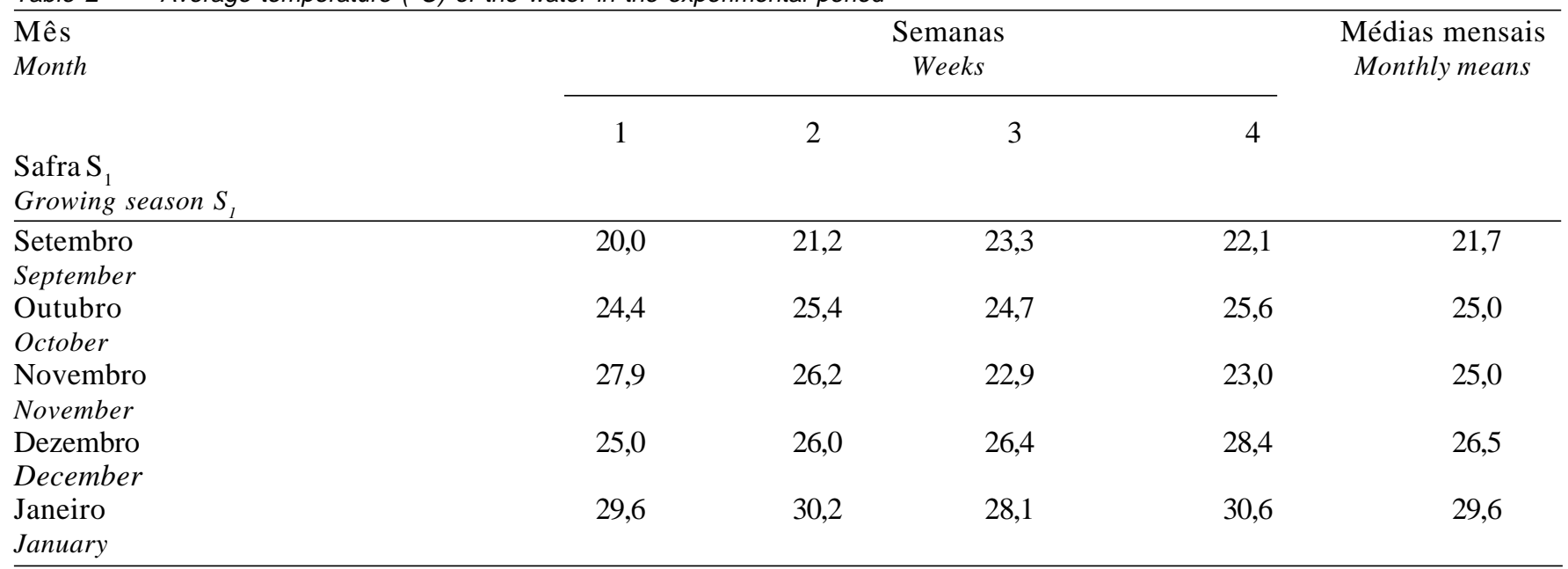

Média da Safra $\mathrm{S}_{1}$

Average of growing season $S_{1}$

\begin{tabular}{|c|c|c|c|c|c|}
\hline Fevereiro & 30,3 & 30,3 & 27,9 & 27,9 & 29,1 \\
\hline February & & & & & \\
\hline Março & 27,0 & 26,6 & 28,3 & 26,2 & 27,0 \\
\hline March & & & & & \\
\hline Abril & 28,7 & 25,4 & 27,3 & 24,0 & 26,4 \\
\hline April & & & & & \\
\hline $\begin{array}{l}\text { Maio } \\
\text { May }\end{array}$ & 22,8 & 22,9 & 21,3 & 19,5 & 21,5 \\
\hline $\begin{array}{l}\text { Junho } \\
\text { June }\end{array}$ & 16,5 & - & - & - & 16,5 \\
\hline
\end{tabular}

Média da Safra $\mathrm{S}_{2}$ 25,5

Average of growing season $S_{2}$

Média geral $\left(\right.$ Safra $\left.\mathrm{S}_{1}+\mathrm{S}_{2}\right)$

24,8

Overall mean (Growing season $S_{1}+S_{2}$ ) 
1270 Rev. bras. zootec.

Tabela 3 - Pesos individuais (inicial e final), ganho de peso, conversão alimentar aparente, taxa de sobrevivência, rendimento de carcaça, biomassa (inicial e final) e ganho de biomassa em duas Safras $\left(S_{1}\right.$ e $\left.S_{2}\right)$ e duas densidades de estocagem $\left(D_{1}\right.$ e $\left.D_{2}\right)$

Table 3 - Initial and final weight, weight gain, apparent feed:gain ratio, survival rate, carcass yield, initial and final biomass, biomass gain in two $\left(S_{1}\right.$ and $\left.S_{2}\right)$ growing seasons and two stocking rates $\left(D_{1}\right.$ and $\left.D_{2}\right)$

Características

Characteristics

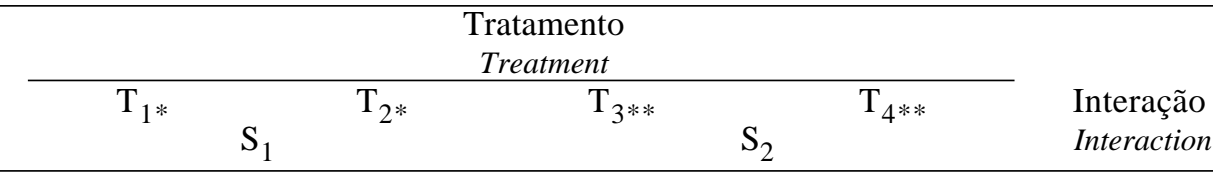

Peso individual inicial (g)

Individual initial weight $(g)$

Peso individual final (g)

Individual final weight $(g)$

Ganho de peso individual ( $\mathrm{g}$ )

Individual weight gain ( $g$ )

Conversão alimentar aparente***

Apparent feed: gain ratio

Taxa de sobrevivência (\%)***

Survival rate (\%)

Rendimento de carcaça $(\%) * * *$

Carcass yield (\%)

Biomassa inicial $\left(\mathrm{g} / \mathrm{m}^{2}\right)$

Initial biomass $\left(\mathrm{g} / \mathrm{m}^{2}\right)$

Biomassa final $\left(\mathrm{g} / \mathrm{m}^{2}\right)$

Final biomass $\left(\mathrm{g} / \mathrm{m}^{2}\right)$

Ganho de biomassa $\left(\mathrm{g} / \mathrm{m}^{2}\right)$

Biomass gain $\left(\mathrm{g} / \mathrm{m}^{2}\right)$

. $T_{1}, T_{2}=$ Safra $S_{1}$ e densidades de estocagem de 0,5 e 0,75 peixes $/ \mathrm{m}^{2}$

$. . T_{3}, T_{4}=$ Safra $S_{2}$ e densidades de estocagem de 0,5 e 0,75 peixes $/ \mathrm{m}^{2}$.

a, b, $c=$ Médias nas linhas seguidas da mesma letra não diferem $(P<0,05)$ pelo teste Tukey.

$(\ldots)=$ Características não-analisadas estatisticamente.

NS = Não-significativo.

$. T_{1}, T_{2}=$ Growing season $S_{1}$ and stocking rates of 0.5 and 0.75 fishes $/ \mathrm{m}^{2}$.

.. $T_{3}, T_{4}=$ Growing season $S_{2}$ and stocking rates of 0.5 and $0.75 \mathrm{fish} / \mathrm{m}^{2}$.

$a, b, c=$ Means, in a row, followed by the same letter, do not differ $(P<.05)$ by Tukey test.

(...) = Characteristics not statistically analyzed.

NS $\quad=$ Non significant.

a 550,2 g no tratamento referente à Safra $\mathrm{S}_{1}$ com 0,5 peixes $/ \mathrm{m}^{2}$.

Houve efeito significativo $(\mathrm{P}<0,05)$ para safra sobre os pesos individuais finais, evidenciando superioridade da safra $S_{1}$ sobre a $S_{2}$. No entanto, não houve efeito significativo $(\mathrm{P}<0,05)$ para densidade de estocagem e efeito interativo entre as duas variáveis.

A conversão alimentar aparente foi semelhante entre todos os tratamentos, variando de 1,3 a 1,4 ; já as taxas de sobrevivência foram, em média, de $96 \%$. O rendimento de carcaça variou de 52,9\% (tratamento 3 ) a $58,8 \%$ (tratamento 4 ).

Os pesos das biomassa iniciais foram de 28,9; 43,$4 ; 43,0$; e $60,0 \mathrm{~g} / \mathrm{m}^{2}$, respectivamente, para os tratamentos T1, T2, T3 e T4. Os pesos finais de biomassa foram de 298,0;397,9; 132,9; e $179,9 \mathrm{~g} / \mathrm{m}^{2}$, respectivamente, para os tratamentos $\mathrm{T} 1, \mathrm{~T} 2, \mathrm{~T} 3 \mathrm{e}$ T4.

Houve efeito significativo $(\mathrm{P}<0,05)$ para safras e densidades de estocagem sobre as características de biomassa final e ganho de biomassa $\left(\mathrm{g} / \mathrm{m}^{2}\right)$. Pode-se afirmar que a utilização da densidade de 0,75 peixes $/ \mathrm{m}^{2}$ produziu significativamente mais biomassa e ganhos de biomassa $(\mathrm{P}<0.05)$ que os tratamentos com 0,5 peixes $/ \mathrm{m}^{2}$. O mesmo pode-se dizer quanto ás safras, já que biomassa final e ganho de biomassa $\left(\mathrm{g} / \mathrm{m}^{2}\right)$ foram superiores $(\mathrm{P}<0,05)$ na Safra $\mathrm{S}_{1}$, quando comparado à Safra $S_{2}$. Não houve interação significativa entre safras $\left(\mathrm{S}_{1}\right.$ e $\left.\mathrm{S}_{2}\right)$ e densidades de estocagem $(0,5$ e 0,75 peixes $/ \mathrm{m}^{2}$ ).

Quanto ao experimento 2, com os dados compilados na Tabela 4, os valores de peso individual final foram, em média, de 849,6 g, sendo de 941,1 e 758,1 $\mathrm{g}$, respectivamente, para as densidades de estocagem 0,5 e 0,75 peixes $/ \mathrm{m}^{2}$.

Os valores de ganhos de peso foram de 885,1 e $701,2 \mathrm{~g}$, respectivamente, para os tratamentos com densidades de estocagem de 0,50 e 0,75 peixes $/ \mathrm{m}^{2}$, com média de 793,1 g. A conversão alimentar aparen- 
te foi semelhante ao experimento 1, com média de 1,3. O rendimento de carcaça foi, em média, de $60,3 \%$.

Os valores de biomassa inicial e final e ganho de biomassa, foram, respectivamente, de 28,6 e 42,7 ; $491,7 \mathrm{e} 578,1 ; 463,1 ; \mathrm{e} 535,4 \mathrm{~g} / \mathrm{m}^{2}$ para as densidades de estocagem de 0,5 e 0,75 peixes $/ \mathrm{m}^{2}$. Não houve diferença estatística significativa $(\mathrm{P}<0,05)$ entre os dois tratamentos para as características observadas.

Analisando as médias semanais e mensais das temperaturas anotadas às 10 e 16 horas, constata-se que houve evolução das mesmas a partir do mês de setembro $\left(20^{\circ} \mathrm{C}\right)$ até um máximo de $30,6^{\circ} \mathrm{C}$ no final da safra $\mathrm{S}_{1}$. Na safra $\mathrm{S}_{2}$ as temperaturas involuiram de $30,3^{\circ} \mathrm{C}$, no início de fevereiro, para $16,5^{\circ} \mathrm{C}$, na primeira semana do mês de junho, quando o experimento foi encerrado.

O oxigênio dissolvido esteve, aparentemente, em padrões compatíveis com o desenvolvimento da espécie em estudo. Os níveis mais baixos foram superiores aqueles relatados por LORIO (1994), que, com a densidade de estocagem de 0,75 peixes $/ \mathrm{m}^{2}$, encontrou concentrações que variaram de 4,1 a 4,4 mg/L. MUNSIRI e LOVELL (1993) encontraram níveis de oxigênio dissolvido freqüentemente abaixo de $3 \mathrm{mg} / \mathrm{L}$, no entanto, a densidade de estocagem era de 1,3 peixes $/ \mathrm{m}^{2}$. LEWIS (1985) afirmou que os níveis de oxigênio dissolvido não deveriam ser inferiores a $4 \mathrm{mg} / \mathrm{L}$ e que o crescimento do catfish pode ser severamente comprometido, se mantido por longo período em ambientes com níveis de oxigênio inferiores a $3 \mathrm{mg} / \mathrm{L}$. No entanto, BROWN e ROBINSON (1989) obtiveram bons resultados no crescimento de catfish com taxas de oxigênio dissolvido que variaram de 1,4 a 7,8 mg/L.

O nível desejável de amônia seria pouco inferior aos máximos encontrados. Também BROWN e ROBINSON (1989) detectaram níveis de amônia variando de 0,1 a $0,9 \mathrm{mg} / \mathrm{L}$ em experimento com catfish na densidade de 0,75 peixes $/ \mathrm{m}^{2}$. Os teores de nitrito e a transparência da água nos viveiros estiveram sempre dentro dos níveis recomendados por TUCKER (1985) e encontrados por ESQUIVEL GARCIA (1992) e LORIO (1994).

Considerando as densidades de estocagem utilizadas, pode-se afirmar que os pesos individuais à despesca na Safra $S_{1}$ estão de acordo com os resultados obtidos por diversos pesquisadores (PIEDRAS, 1990; LEWIS, 1985; e LEE, 1991). LEWIS (1985) apresenta tabela evolutiva de cultivos de catfish no sul dos Estados Unidos, a partir de juvenis de $18 \mathrm{~g}$, quando a temperatura da água evoluiu de 20 para $30^{\circ} \mathrm{C}$ e decresceu até $23^{\circ} \mathrm{C}$ ao final de seis meses. A média de peso dos animais foi aproximadamente, de 500 g. MUNSIRI e LOVELL (1993), a partir de juvenis com $47 \mathrm{~g}$ de peso em densidade de estocagem de 1,3 peixes $/ \mathrm{m}^{2}$, durante 15 semanas, encontraram pesos individuais finais que variaram de $464 \mathrm{a} 603 \mathrm{~g}$, dependendo do nível de proteína bruta utilizada. Notase que o experimento contemplava altos níveis de aeração e renovação de água e as dietas eram extrusadas. LORIO (1994) observou resultados semelhantes, na densidade de estocagem de 0,74 peixes/ $\mathrm{m}^{2}$. BROWN e ROBINSON (1989), no entanto, utilizando juvenis com $21 \mathrm{~g}$ e densidade de 0,74 peixes $/ \mathrm{m}^{2}$, encontraram pesos individuais à despesca variando de 345 a $363 \mathrm{~g}$, em seis meses de cultivo.

ESQUIVEL GARCIA (1992) verificou valores de pesos à despesca de 727,1 e 646,6 g, respectivamente, para as densidades de estocagem de 0,5 e 0,75 peixes $/ \mathrm{m}^{2}$, em nove meses de cultivo, no período de abril a dezembro. Nas mesmas densidades de estocagem e com duração idêntica (Safra única), os

Tabela 4 - Pesos individuais (inicial e final), ganho de peso, conversão alimentar aparente, taxa de sobrevivência, rendimento de carcaça, biomassa (inicial e final) e ganho de biomassa em safra única e duas densidades de estocagem

Table 4 - Initial and final weight, weight gain, feed:gain ratio, survival rate (\%), carcass yield, initial and final biomass gain in the unique growth season and two stocking rates

\begin{tabular}{|c|c|c|c|}
\hline \multirow[t]{2}{*}{$\begin{array}{l}\text { Características } \\
\text { Characteristics }\end{array}$} & \multicolumn{3}{|c|}{$\begin{array}{c}\text { Tratamento } \\
\text { Treatment } \\
\end{array}$} \\
\hline & $\mathrm{T}_{5 *}$ & $\mathrm{~T}_{6 * *}$ & $\begin{array}{l}\text { Média } \\
\text { Mean }\end{array}$ \\
\hline $\begin{array}{l}\text { Peso inicial }(\mathrm{g}) \\
\text { Initial weight }(\mathrm{g})\end{array}$ & 57,1 & 56,9 & 57,0 \\
\hline $\begin{array}{l}\text { Peso final }(\mathrm{g}) \\
\text { Final weight }(g)\end{array}$ & 941,1 & 758,1 & 849,6 \\
\hline $\begin{array}{l}\text { Ganho de peso }(\mathrm{g}) \\
\text { Weight gain }(g)\end{array}$ & 885,1 & 701,2 & 793,1 \\
\hline $\begin{array}{l}\text { Conversão alimentar aparente*** } \\
\text { Apparentfeed:gain ratio }\end{array}$ & 1,3 & 1,4 & 1,3 \\
\hline $\begin{array}{l}\text { Taxa de sobrevivência }(\%)^{* * *} \\
\text { Survival rate (\%) }\end{array}$ & 100,0 & 97,0 & 98,0 \\
\hline $\begin{array}{l}\text { Rendimento de carcaça }(\%)^{* * *} \\
\text { Carcass yield }(\%)\end{array}$ & 60,0 & 60,7 & 60,3 \\
\hline $\begin{array}{l}\text { Biomassa inicial }\left(\mathrm{g} / \mathrm{m}^{2}\right) \\
\text { Initial biomass }\left(\mathrm{g} / \mathrm{m}^{2}\right)\end{array}$ & 28,6 & 42,7 & 35,6 \\
\hline $\begin{array}{l}\text { Biomassa final }\left(\mathrm{g} / \mathrm{m}^{2}\right) \\
\text { Final biomass }\left(\mathrm{g} / \mathrm{m}^{2}\right)\end{array}$ & 491,7 & 578,1 & 534,5 \\
\hline $\begin{array}{l}\text { Ganho de biomassa }\left(\mathrm{g} / \mathrm{m}^{2}\right) \\
\text { Biomass gain }\left(\mathrm{g} / \mathrm{m}^{2}\right)\end{array}$ & 463,1 & 535,4 & 499,2 \\
\hline
\end{tabular}

(.) $\mathrm{T}_{5}$ = Densidade de estocagem de 0,5 peixes $/ \mathrm{m}^{2}$.

(..) $\mathrm{T}_{6}^{5}=$ Densidade de estocagem de 0,75 peixes $/ \mathrm{m}^{2}$.

(....) ${ }^{6}=$ Características não analisadas estatisticamente.

(.) $T 5=$ Stocking rates $\left(0.5\right.$ fishes $\left./ \mathrm{m}^{2}\right)$.

(..) $T 6$ = Stocking rates $\left(0.75\right.$ fishes $\left./ \mathrm{m}^{2}\right)$.

(...) = Characteristics not statistically analyzed. 
1272 Rev. bras. zootec.

valores de peso individual médio encontrados neste trabalho foram significativamente superiores $(942,2$ e $758,1 \mathrm{~g}$, para 0,5 e 0,75 peixes $/ \mathrm{m}^{2}$, respectivamente). Esta diferença foi provavelmente motivada pelo período de cultivo diferente (abril a dezembro).

Experimentos de cultivos com duração superior a cinco ou seis meses são escassos e quase sempre se referem a cultivos de duas ou mais estações de crescimento, correspondendo a períodos dois ou mais anos.

ESQUIVEL GARCIA (1992), REIS et al (1989), GANNAM e LOVELL (1990) e MUNSIRI e LOVELL (1993) encontraram taxas de conversão alimentar que variaram de 1,03 a 1,6 enquanto BROWN e ROBINSON (1989) encontraram valores que variaram de 1,61 a 1,78.

As taxas de sobrevivência foram, de forma geral, comparáveis às encontradas por diversos autores (ESQUIVEL GARCIA, 1992; BROWN e ROBINSON, 1989; MELOTTI et al, 1992; e BRANCH e TILLEY 1992).

LOVELL (1989) afirmou que, para dietas com $32 \%$ de proteína bruta, o rendimento de carcaça deveria situar-se entre 54,5 e $56,6 \%$. LOVELL e LI (1992) no entanto, encontraram em peixes de dois e três anos, rendimentos de carcaça entre 60,8 e 66,3\%. Outros autores relataram índices oscilando entre 51,8 e 63,8\% (MUNSIRI e LOVELL,1993; GANNAM e LOVELL,1990; e BROWN e ROBINSON,1989).

Os resultados de biomassas finais na Safra $S_{1}$ para densidade de estocagem de 0,5 e 0,75 peixes $/ \mathrm{m}^{2}$ são semelhantes aos encontrados por BROWN e ROBINSON (1989), GANNAM e LOVELL (1990) e LORIO (1994), que encontraram valores que oscilaram de 258 a $594 \mathrm{~g} / \mathrm{m}^{2}$.

ESQUIVEL GARCIA (1992), em nove meses de cultivos, obteve biomassas finais de 352 e $454 \mathrm{~g} / \mathrm{m}^{2}$, respectivamente, para as densidades de estocagem de 0,5 e 0,75 peixes $/ \mathrm{m}^{2}$, inferiores, portanto, aos encontrados neste trabalho. Similarmente ao observado quanto ao peso individual médio, esta variação foi devida à diferença de época de cultivo.

As biomassas referentes à safra $\mathrm{S}_{2}$ foram inferiores às da safra $S_{1}$. As causas podem ser atribuídas ao período mais curto de cultivo e, também, à temperatura inferior da água, principalmente a partir do mês de maio.

\section{Conclusões}

O cultivo do Ictalurus punctatus pode ser recomendado para as condições climáticas do litoral de Santa Catarina, na densidade de estocagem de 0,75 peixes $/ \mathrm{m}^{2}$, em cultivos de cinco meses no período de primavera-verão. Para cultivo de nove meses (primavera-verão-outono), as densidades de estocagem de 0,50 e 0,75 peixes $/ \mathrm{m}^{2}$ apresentaram resultados similares.

\section{Referências Bibliográficas}

BRANCH, W., TILLEY, D.S. Oklahoma net-pen catfish production systems: estimated production level and costs. In: AQUACULTURE' 92 - GROWING TOWARD THE $21^{\text {st }}$ CENTURY, Orlando, Florida, 1992. Proceedings... Orlando, 1992. p.157 (Abstract).

BROWN, P.B., ROBINSON R. 1989. Comparison of practical catfish feeds containing 26 or $30 \%$ protein. The Progress Fish Cult., 51:149-151.

ESQUIVEL GARCIA, J.R.E. Crescimento do Ictalurus punctatus (Rafinesque, 1820) em quatro densidades de estocagem nas condições climáticas do litoral de Santa Catarina-Brasil. Florianópolis, SC: UFSC. 1992. 60p. Dissertação (Mestrado em Aqüicultura) - Universidade Federal de Santa Catarina, 1992.

GANNAM, A.L., LOVELL, R.T. 1990. Growth and bone development in channel catfish feed 17-a-methyltestoterone in production ponds. J.World Aquac. Soc., 22(2):95-100.

LEE, J.S. 1991. Commercial catfish farming. Danville, Illinois: Interstate Publisher, Inc. 330p.

LEWIS, G.W. 1985. Channel catfish production in ponds. Coop. Extension Service. University of Georgia-College of Agriculture. Athens MB: 103. 14p.

LORIO, W.J. 1994. Production of channel catfish in pond with water recirculation. Progr. Fish Cult., 56:202-206.

LOVELL, R.T., LI, M. 1992. Comparison of feed conversion, dressing yield and muscle composition for second and thirtyyear channel catfish. Progr. Fish Cult., 54(3): 171-173.

LOVELL, T. 1989. Nutrition and feeding offish. New York: Van Nostrand Reinhold. 260p.

MELOTTI, P., RONCARATI, A., BELVEDERE, P. et al. 1992. Channel catfish (Ictalurus punctatus) culture in Italy at different stocking densities with/without mechanical aeration. In: AQUACULTURE' 92 - GROWING TOWARD THE $21^{\text {st }}$ CENTURY, Orlando, Florida, 1992. Proceedings... Orlando, 1992. p.160-161. (Abstract).

MUNSIRI, P., LOVELL, T. 1993. Comparison of satiate and restricted feeding of channel catfish with diets of varying protein quality in production ponds. J. World Aquac. Soc., 24(4):459-465.

NEW, M.B. 1987. Feed and feeding of fish and shrimp. Rome: FAO. $117 \mathrm{p}$.

NATIONAL RESEARCH COUNCIL - NRC. 1988. Nutrient requirements of warmwater fishes and shelfishes. Washington: National Academy Press. 102p.

PIEDRAS, S.R. 1990. Manual prático para o cultivo do channel catfish (Ictalurus punctatus). Pelotas: Educat. $74 \mathrm{p}$.

REIS, L.M., REVTEBVCH, E.M., LOVELL, R.T. 1989. Proteinto-energy ratios in production diets and growth, feed conversion and body composition of channel catfish, I. puntactus. Aquaculture, 77(1):21-27.

TUCKER, C.S. 1985. Channel catfish culture. New York: Elsevier. 665p.

Recebido em: $21 / 08 / 98$

Aceito em: 19/04/00 